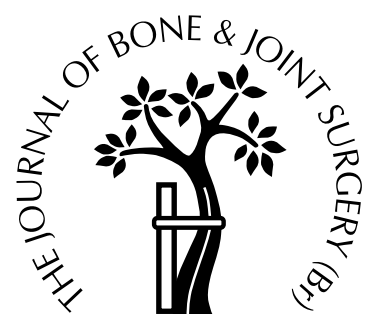

\title{
Intravenous pamidronate reduces osteoporosis and improves formation of the regenerate during distraction osteogenesis
}

\author{
A STUDY IN IMMATURE RABBITS \\ D. G. Little, M. S. Cornell, J. Briody, C. T. Cowell, S. Arbuckle, \\ C. M. Cooke-Yarborough \\ From the Royal Alexandra Hospital for Children and the University of Sydney, Australia
}

W e examined the effect on bone mineral density (BMD) of a single dose of $3 \mathrm{mg} / \mathrm{kg}$ of the bisphosphonate, pamidronate (Novartis) in distraction osteogenesis in immature rabbits.

Seventeen rabbits ( 9 control, 8 given pamidronate) were examined by dual-energy $x$-ray absorptiometry. There was a significant increase in the BMD in the pamidronate group compared with the control animals. The mean areal BMD $\left(\mathrm{g} / \mathrm{cm}^{2}\right)$ in the bone proximal and distal to the regenerate was increased by $40 \%$ and $39 \%$, respectively, compared with the control group $(p<0.05)$. The BMD of the regenerate bone was increased by a mean of $43 \%(p<0.05)$. There was an increase of $22 \%$ in the mean area of regenerate formed in the pamidronate group $(\mathbf{p}<0.05)$.

Histological examination of bone in nine rabbits $(5$ control, 4 pamidronate) showed an increase in osteoblastic rimming and mineralisation of the regenerate, increased formation of bone around the pin sites and an increase in the cortical width of the bone adjacent to the regenerate in the rabbits given pamidronate.

Pamidronate had a markedly positive effect. It reduced the disuse osteoporosis normally associated with lengthening using an external fixator and increased the amount and density of the regenerate bone. Further study is required to examine the

D. G. Little, FRACS (Orth), Clinical Lecturer, Head, Orthopaedic Research Unit

Department of Paediatrics and Child Health

M. S. Cornell, FRCS (Tr \& Orth), Ingham Orthopaedic Fellow

Department of Orthopaedics

J. Briody, MBioMedEng, Scientific Officer

Department of Nuclear Medicine

C. T. Cowell, FRCP(C), FRACP, Consultant Endocrinologist

Department of Endocrinology

S. Arbuckle, FRCPA, Consultant Histopathologist

C. M. Cooke-Yarborough, FRCPA, Consultant Histopathologist

Department of Histopathology

Royal Alexandra Hospital for Children, Hawkesbury Road, Westmead, New South Wales 2145, Australia.

Correspondence should be sent to Dr D. G. Little.

(C)2001 British Editorial Society of Bone and Joint Surgery 0301-620X/01/710542\$2.00 mechanical properties of the regenerate after the administration of pamidronate.

J Bone Joint Surg [Br] 2001;83-B:1069-74

Received 7 September 1999; Accepted after revision 21 July 2000

The stability of the external fixator during distraction osteogenesis is essential for the reliable production of new bone. ${ }^{1,2}$ Since the fixator takes much of the load during the lengthening and the patient may not be fully mobile, osteoporosis develops in the bone adjacent to the site of lengthening. In a study of ten lengthened segments in children, Eyres, Bell and Kanis ${ }^{3}$ noted a mean decrease in bone mineral density (BMD) of $44.2 \%$ in the tibia and $61.0 \%$ in the femur distal to the lengthening site. Recent advances in the pharmacological treatment of osteoporosis with bisphosphonates have encouraged us to explore their use in limb lengthening. ${ }^{4-8}$

Our aim was to investigate the effect of pamidronate on reducing osteoporosis during tibial lengthening in immature rabbits. Its effect on the mineralisation of regenerate new bone was also examined.

\section{Materials and Methods}

Experimental design. Ethical approval for this project was granted by the Institutional Animal Ethics Committee.

We performed tibial lengthening in 20 28-week-old male New Zealand White rabbits. Similar studies in rabbits have been reported. ${ }^{9,10}$ After premedication with intramuscular ketamine $(15 \mathrm{mg} / \mathrm{kg})$ and xylazine $(4 \mathrm{mg} / \mathrm{kg})$, anaesthesia was administered with halothane $2 \%$ and oxygen at $11 / \mathrm{min}$. After preparation of the right lower limb we performed an open mid-tibial drill-hole osteotomy and applied an Orthofix M-100 fixator using four Orthofix $3 \mathrm{~mm}$ half pins (Orthofix, Bussolengo, Italy). The left lower limb was left intact. After a period of 24 hours the tibia was lengthened by $0.375 \mathrm{~mm}$ every 12 hours for 15 days, producing distraction of $11.25 \mathrm{~mm}$. The fixator was then left in situ for 27 days to allow the regenerate to consolidate. Ten control animals were operated on and given infusions of saline only. These rabbits were operated on first to establish that the model produced considerable osteoporosis in the bone adjacent to the regenerate. Pamidronate, $3.0 \mathrm{mg} / \mathrm{kg}$ diluted 
to $30 \mathrm{mg} / 100 \mathrm{ml}$, was administered as a single intraoperative infusion over two hours in the next ten rabbits. In all animals buprenorphine $0.05 \mathrm{mg} / \mathrm{kg}$ was administered at the end of surgery and again 12 hours later.

The animals were supplied with rabbit pellets and water ad libitum. At 42 days they were killed with intravenous Valabarb (pentobarbitone sodium; Jurox, Silverwater, NSW, Australia) $(150 \mathrm{mg} / \mathrm{kg})$.

Radiological and BMD analysis. Both hind limbs were disarticulated through the knee and the soft tissues left intact. The limbs were orientated in standard AP and lateral projections and plain radiographs taken with a Siemens Multix H/UPH (Siemens Aktiengesellschaft, Munich, Germany) configuration using digital luminescent cassettes with a $50 \mathrm{kV}$ and $4 \mathrm{~mA}$ exposure and a tube-to-film distance of $1.1 \mathrm{~m}$. The distance between the pin sites was measured from each dissected specimen so that each radiograph could be rescaled appropriately for measurements of the length of regenerate.

Measurements of BMD were made using a total-body dual-energy x-ray densitometer (DXA) (LUNAR DPX; Radiation Corporations, Madison, Wisconsin). The technique has been used in this context in previous reports. ${ }^{11}$ BMD scans were performed with the tibia orientated in the anteroposterior (AP) and lateral projections, using software specifically designed for measurement in small animals ${ }^{12}$ (LUNAR DPX Small Animal Software, 1.0c LUNAR; Radiation Corporations). The 'HiRes $<0.5$ kg Slow' scan mode was used with 'Fine' collimation, a sample size of $0.6 \times 1.2 \mathrm{~mm}$, and a sample interval of $1 / 16$. In order to calculate the coefficient of variation of the machine, 30 scans were performed on a rabbit forelimb over the duration of the period of study. The coefficients of variation of the BMD measured by positioning three boxes on each scan were $3.6 \%, 4.5 \%$ and $5.7 \%$ (proximal to distal).

Regional measurements of BMD were obtained by placing 'regions of interest' (ROIs) $9.6 \mathrm{~mm}$ high on the scan images. For each lengthened tibia, one ROI was positioned in the regenerate, one proximal to it and one distal to it. In the non-operated tibia, two ROIs were placed so that they matched the distal and proximal ROIs of the lengthened tibia (i.e., the same distance from the bone ends). A total of three measurements was thus generated for each lengthened tibia and two measurements for each non-operated tibia, for each projection. Values for the BMD were expressed as $\mathrm{g} / \mathrm{cm}^{2}$ and group data reported as the mean and standard deviation. Lengthened and non-operated tibial samples were compared using paired $t$-tests and non-paired tests to compare between groups.

Histological analysis. This was performed in a blinded fashion by two of the authors (CCY and SA). Five pairs of tibiae from the pamidronate group and five from the control animals were excised subperiosteally and fixed in $10 \%$ buffered formalin. Each bone was sectioned transversely into proximal, regenerate and distal bone segments before decalcification in a standard EDTA solution over 48 hours.
Each segment was then sliced longitudinally and halfembedded in paraffin yielding six blocks per rabbit. Sections for microscopy were cut at $5 \mu \mathrm{m}$ and stained with haematoxylin and eosin. Both pathologists examined all the sections and made a consensus assessment of the amount of formation of new bone and the extent of remodelling in the regenerate, the cortical thickness, and the formation of bone around the pin sites. The cortical thickness was not measured precisely since it would be expected to alter depending on the plane of sectioning. The activity of osteoclasts in the regenerate was expressed as the number per high-power field (HPF) (Olympus BH2, $40 \times$ objective; Olympus Optical Co, Tokyo, Japan).

\section{Results}

Exclusions. There were three postoperative complications which necessitated exclusion from the DXA analysis: one tibial fracture noted on the first day near the distal pin sites (pamidronate group), one femoral fracture on day 23 requiring euthanasia (pamidronate group) and one palsy of the common peroneal nerve (control group).

Control group. Reliable formation of bone occurred in the distraction gap. All tibiae were clinically and radiologically united at day 42. Values for the BMD from the AP scan for the lengthened and non-operated limbs are shown in Figure 1. There was a significant reduction in BMD in both the proximal and distal segments surrounding the lengthening compared with the matched sites in the control limb $(p<0.02)$. Similar significant differences were present on the lateral scans.

Pamidronate group. The reduction in BMD in the proximal and distal segments was not found in the pamidronate group, with no significant difference in BMD between the bone of the operated and non-operated limbs at six weeks $(\mathrm{p}=0.332$ proximal, $\mathrm{p}=0.256$ distal) (Fig. 2). The same effect was seen on the lateral scans.

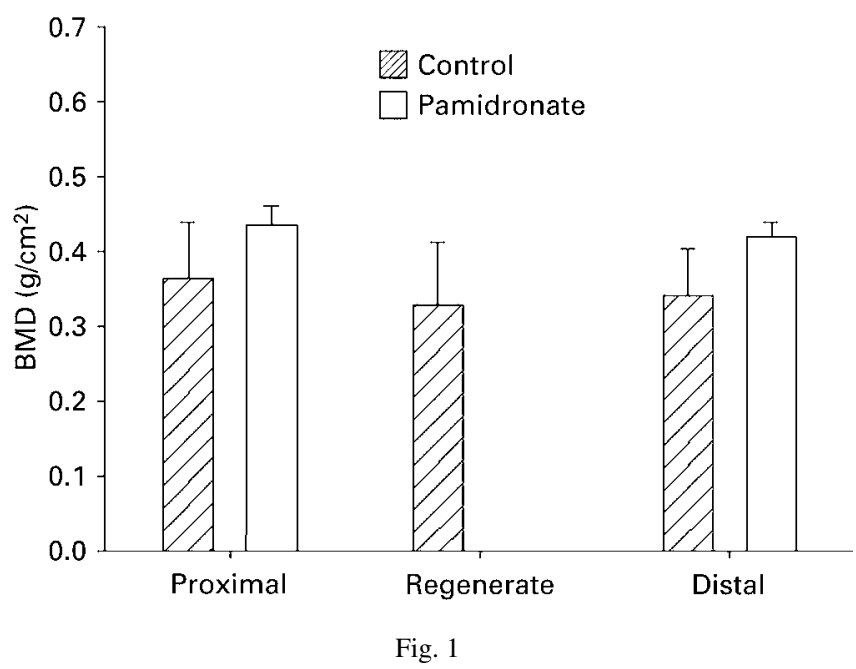

Comparison of the BMD of the lengthened with the non-lengthened limb in the control group. The mean and 95\% confidence interval are shown. 


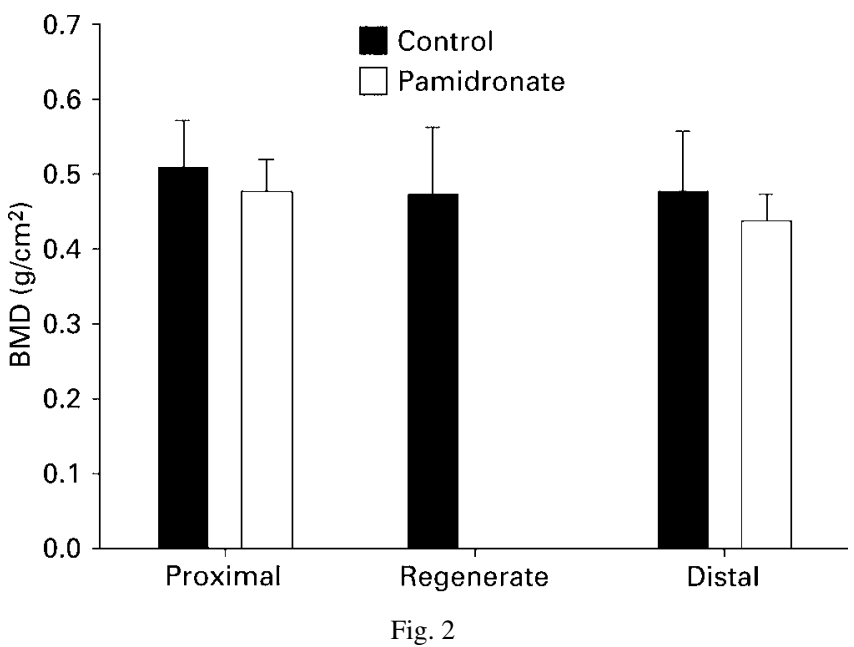

Comparison of the BMD of the lengthened with the non-lengthened limb in the group given pamidronate. The mean and $95 \%$ confidence interval are shown.

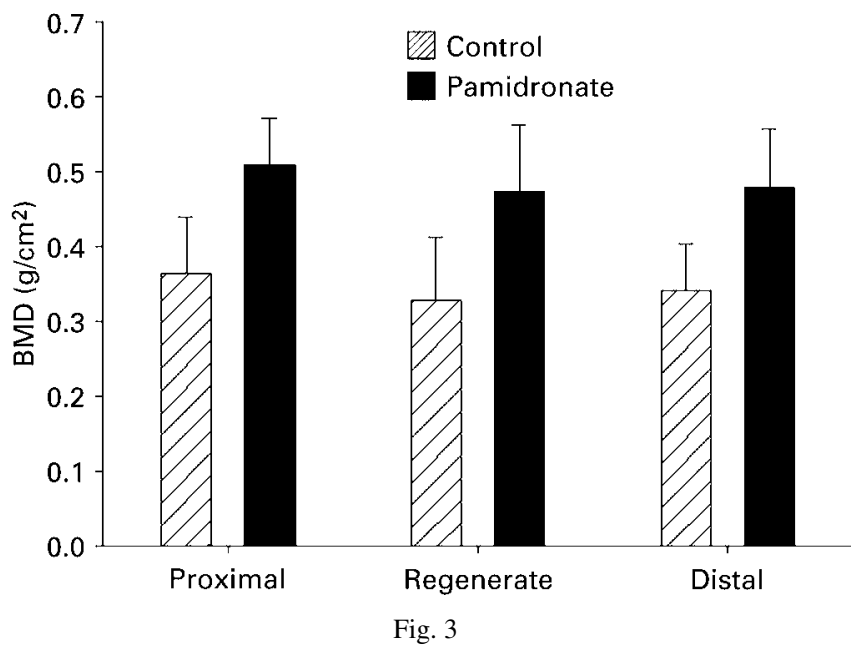

Comparison of the BMD of lengthened limbs in the control group with those in the pamidronate group. The mean and $95 \%$ confidence interval are shown.

Table I. Mean values (SD) for the pamidronate and control groups

\begin{tabular}{lcclll}
\hline Variable & Pamidronate & Control & Difference & 95\% Confidence interval & p value \\
\hline Length of lengthened limb $(\mathrm{mm})$ & $106.0(3.4)$ & $107.6(4.5)$ & -1.57 & -5.76 to 2.63 & 0.44 \\
Length of non-operated limb $(\mathrm{mm})$ & $97.4(2.0)$ & $98.9(2.2)$ & -1.45 & -3.59 to 0.74 & 0.18 \\
Weight of lengthened tibia $(\mathrm{g})$ & $10.9(0.6)$ & $8.7(0.9)$ & 2.2 & 1.37 to 3.03 & $<0.001$ \\
Weight of non-operated tibia $(\mathrm{g})$ & $9.3(0.5)$ & $8.1(0.4)$ & 1.19 & 0.71 to 1.67 & $<0.001$ \\
Regenerate length $(\mathrm{mm})$ & $9.6(0.6)$ & $10.4(0.7)$ & -0.75 & -1.45 to -0.04 & 0.04 \\
Regenerate area $\left(\mathrm{cm}^{2}\right)$ & $0.83(0.09)$ & $0.68(0.13)$ & 0.15 & 0.03 to 0.27 & 0.017 \\
AP BMD proximal to regenerate $\left(\mathrm{g} / \mathrm{cm}^{2}\right)$ & $0.51(0.07)$ & $0.36(0.09)$ & 0.14 & 0.06 to 0.23$)$ & 0.004 \\
AP BMD in regenerate $\left(\mathrm{g} / \mathrm{cm}^{2}\right)$ & $0.47(0.11)$ & $0.33(0.11)$ & 0.14 & 0.03 to 0.25 & 0.017 \\
AP BMD distal to regenerate $\left(\mathrm{g} / \mathrm{cm}^{2}\right)$ & $0.48(0.10)$ & $0.34(0.08)$ & 0.14 & 0.04 to 0.23 & 0.007 \\
AP BMD in proximal non-operated limb $\left(\mathrm{g} / \mathrm{cm}^{2}\right)$ & $0.48(0.05)$ & $0.44(0.03)$ & 0.04 & 0.00 to 0.09 & 0.053 \\
AP BMD in distal non-operated limb $\left(\mathrm{g} / \mathrm{cm}^{2}\right)$ & $0.44(0.04)$ & $0.42(0.02)$ & 0.02 & -0.02 to 0.05 & 0.31 \\
\hline
\end{tabular}

Figure 3 compares the BMD from the AP scans of the operated limbs for rabbits given pamidronate with that of the control group. The BMD of the proximal and distal bone surrounding the regenerate increased by a mean of $40 \%$ and $39 \%$, respectively $(\mathrm{p}<0.01)$. The BMD in the regenerate was increased by a mean of $43 \%$ compared with the control rabbit tibiae $(p=0.017)$. Lateral scans also confirmed the above significant differences.

The BMD for the non-operated limbs of the control and pamidronate groups was not significantly different (Table I). There was an increase in the mean regenerate area of $22 \%$ in the pamidronate group $(\mathrm{p}<0.05)$.

Histological examination. Of the ten specimens collected, nine were examined histologically. The rabbit culled on day 23 was not included in the analysis. The tibiae from the pamidronate group took 24 to 48 hours longer to decalcify than the control specimens. They had increased formation of regenerate with prominent osteoblastic rimming and decreased numbers of osteoclasts (2.4/HPF versus $3.4 / \mathrm{HPF}$ in the control group) with less evidence of bone remodelling (Fig. 4). There was also an increased formation of endosteal bone in the cortex adjacent to the regenerate producing an increase in cortical thickness (Fig. 5), and a marked increase in formation of bone around the pin sites in the pamidronate group. There was a degree of variability in these factors within the pamidronate group, as with the variability seen in BMD values.

\section{Discussion}

Bisphosphonates are characterised by a phosphorus-carbonphosphorus bond which has a strong affinity for bone mineral. They differ in their actions and potency depending on the configuration of a side chain; pamidronate has an amino side chain. Bisphosphonates inhibit bone resorption by a direct effect on the function of osteoclasts and also inhibit the osteoblastic recruitment of osteoclasts. ${ }^{5}$ Calcium is therefore retained in the skeleton and there is a sub- 


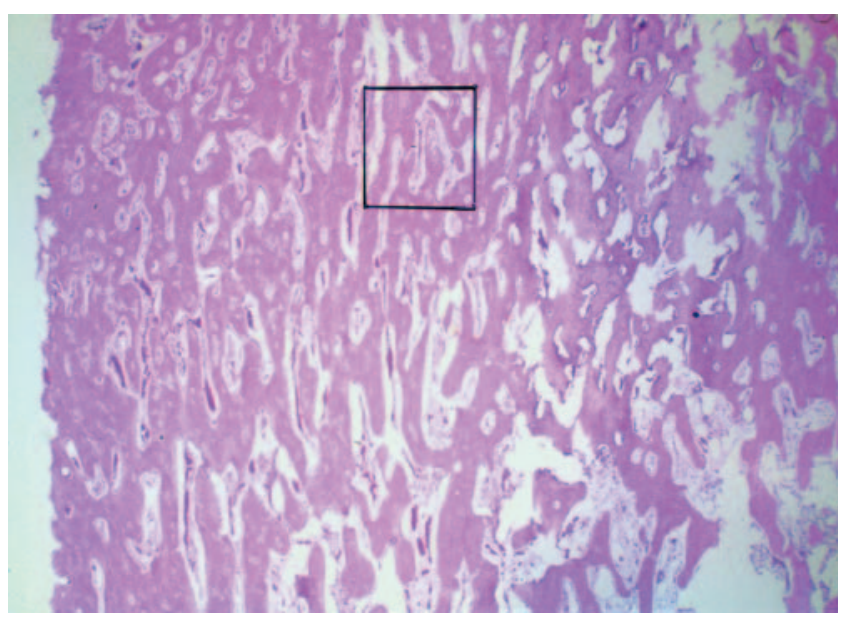

Fig. $4 \mathrm{a}$

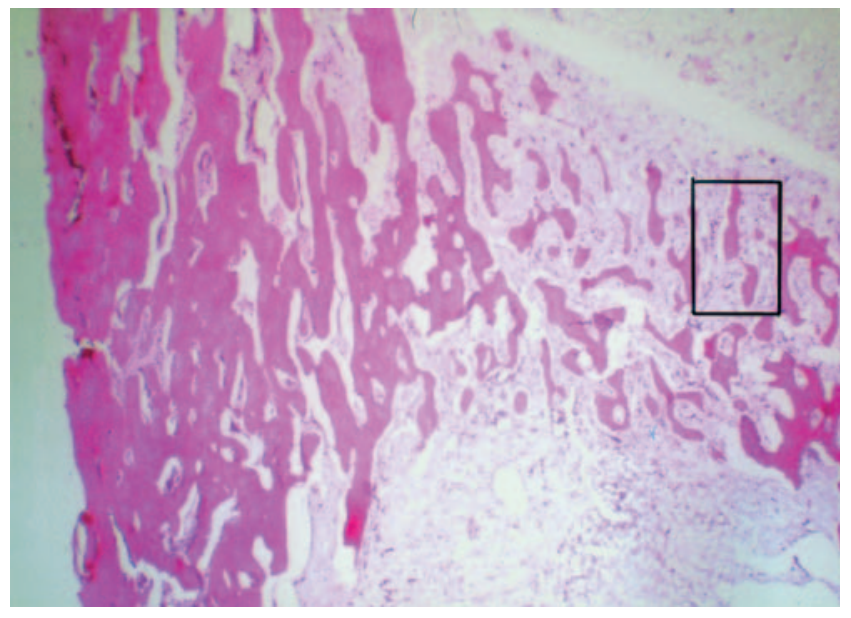

Fig. 4b

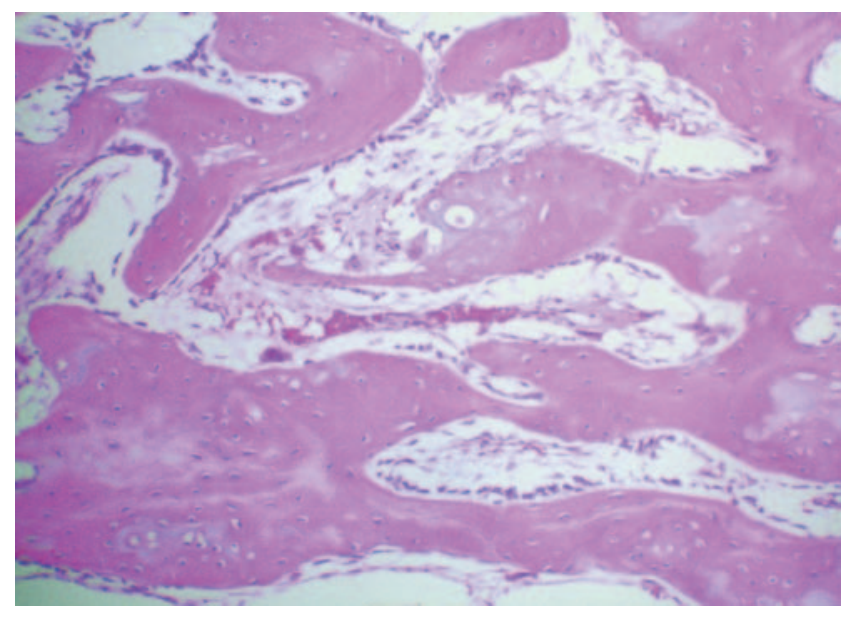

Fig. 4a (inset)

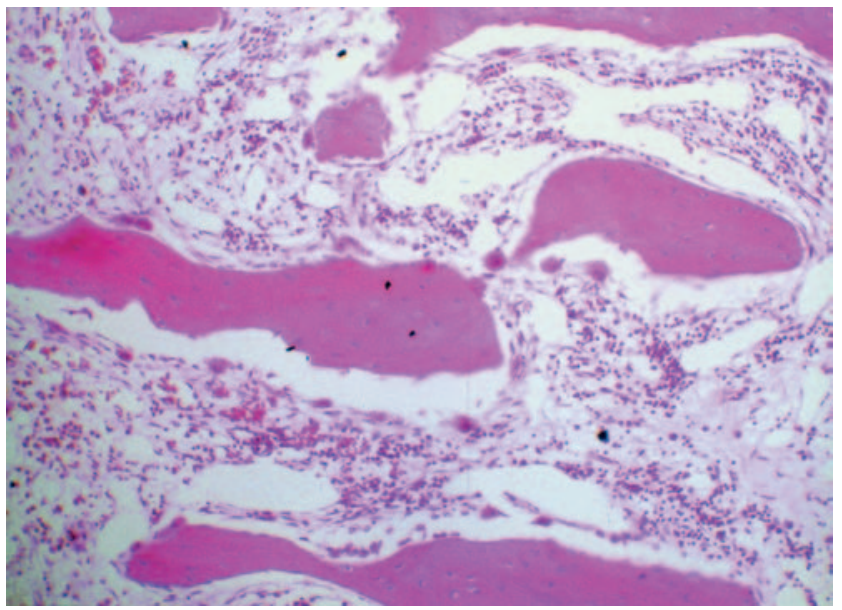

Fig. 4b (inset)

Photomicrographs showing histological comparison of the regenerate. There is increased formation of regenerate in the pamidronate group (a) with prominent osteoblastic rimming of the trabeculae of woven bone and a relative paucity of osteoclasts (a, inset). By contrast, there is less regenerate in the control group (b) with a predominance of osteoclasts around the trabeculae of woven bone associated with scalloping (b, inset) (haematoxylin and eosion; $\mathrm{a}, \times 3$; a, inset, $\times 18 ; \mathrm{b}, \times 3$; b, inset, $\times 18$ )

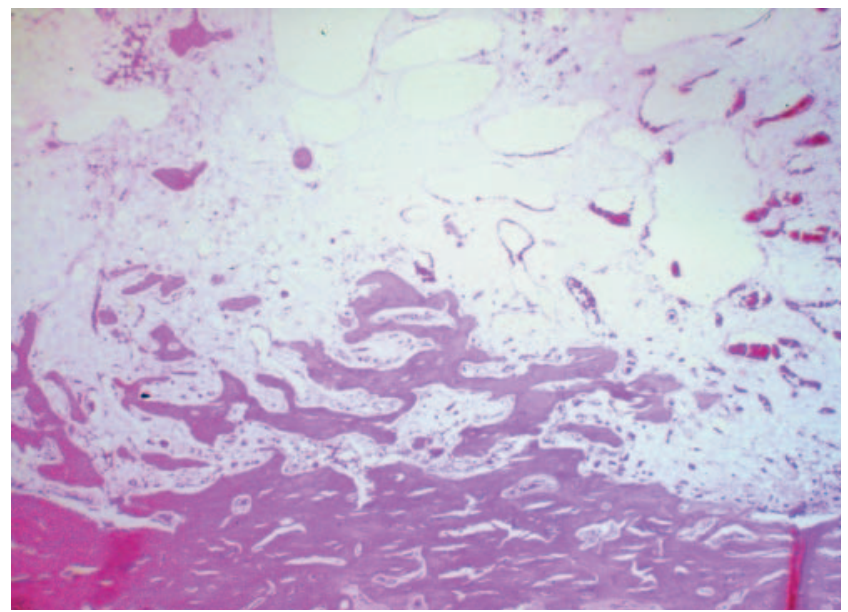

Fig. 5a

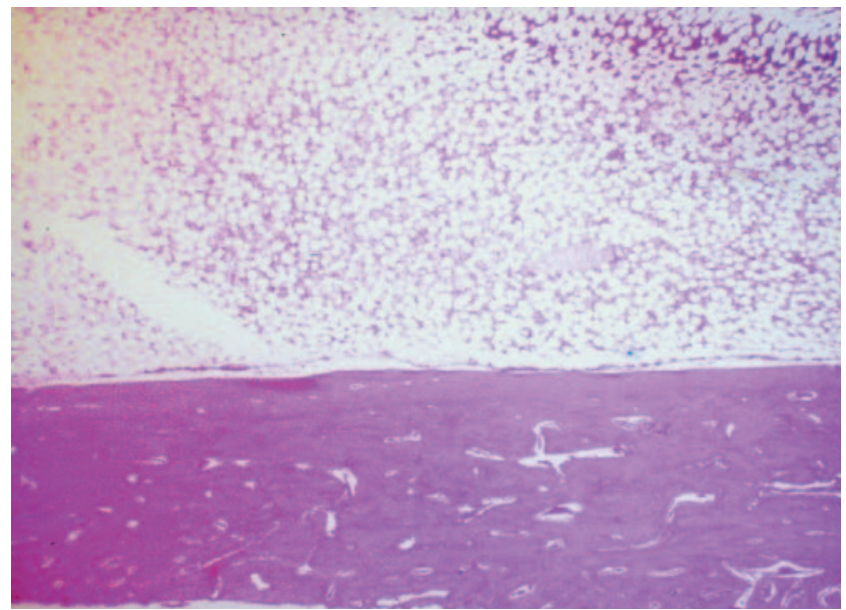

Fig. $5 b$

Photomicrographs showing comparison of the cortex distal to the regenerate. New bone is formed along the endosteal surface of the cortical bone distal to the regenerate in the pamidronate group (a). This is not seen in the control group (b) (haematoxylin and eosin; a, $\times 3$; b, $\times 18$ ). 
sequent increase in parathyroid hormone $(\mathrm{PTH})$ and $1,25-(\mathrm{OH})_{2}$ vitamin $\mathrm{D}$, leading to increased intestinal absorption of calcium. In growing rats this results in an increase in bone mass. In very high doses, bisphosphonates may actually inhibit the formation of bone and the function of osteoblasts.

We gave a single dose of $3 \mathrm{mg} / \mathrm{kg}$ at the beginning of the lengthening specifically to minimise the negative effects on remodelling. This strategy abolished the osteoporosis seen in the control group and had a markedly positive effect on the activity of osteoblasts and accretion of bone mineral in the regenerate. The number and activity of osteoclasts remained reduced at day 42 . Since the pamidronate was given at the time of surgery, the marked increase in the formation of regenerate and mineralisation is most interesting. Either pamidronate from the surrounding bone leached out into the regenerate bone to exert a local effect, or the increase in regenerate was due to an anabolic effect secondary to changes in PTH and $1,25-(\mathrm{OH})_{2}$ vitamin D. Further research is required to evaluate these hypotheses.

We considered that a pulsatile predosage regimen would be desirable when coincident with surgical intervention. As pamidronate has a strong affinity for bone mineral, it is possible to load the skeleton with a pulsatile dose that will exert a positive effect for three to six months. ${ }^{13}$ Goodship et $\mathrm{al}^{14}$ performed a study in sheep with the aim of assessing the effect of pamidronate in fractures around metastases in patients already treated with bisphosphonates. Using a weekly dose of $0.5 \mathrm{mg} / \mathrm{kg}$ for four weeks before and for 12 weeks after surgery, they noted an increase in mineralisation of the callus but decreased remodelling. They found an increase in torsional strength in the treated group. Li et $\mathrm{al}^{15}$ performed a study on rats with the stated aim of testing "whether bisphosphonates disturb the process of fracture healing". They showed increased formation of callus in femoral fractures pretreated with incadronate. Continuation of therapy for 16 weeks after the fracture increased the formation of callus even further, but the new bone did not remodel to form a cortical shell as in the pretreated group. This delay in remodelling was offset by the increased volume of callus, but still produced an improvement in the mechanical properties of the healing bone. Thus there may be an advantage in giving a second dose of bisphosphonate at the end of distraction in this model, but this has yet to be tested.

It was concluded from previous studies using an array of earlier bisphosphonates in fracture models that there was neither a detrimental nor a net negative effect on healing, but in all there was delay in remodelling because osteoclastic inhibition was found. ${ }^{16-21}$ In one previous study, using pamidronate and a distraction model, the dose of pamidronate was only $0.6 \mathrm{mg} / \mathrm{kg}$. The BMD in the surrounding bone was preserved, but this wore off after 15 days and there was no significant change in the regenerate. ${ }^{22}$ Further research on the optimal dose is required.
Apart from the negative effects on remodelling, continuous treatment with bisphosphonates may not be desirable in distraction osteogenesis in children, because of a detrimental effect on longitudinal growth. In a study using daily subcutaneous alendronate, normal growing mice showed a decrease in leg length, as well as decreased ductility after treatment. ${ }^{23}$ We noted no significant change in leg length, although there was a suggestion of inhibition of growth; the non-operated limbs in the control group were longer than those in the pamidronate group by $1.4 \mathrm{~mm}$. We did not have limb measurements at the time of operation and therefore cannot be certain that this difference was due to inhibition of growth. We believe that inhibition was minimised by our one-dose regimen. The study of Li et al ${ }^{15}$ did not comment on longitudinal growth, but the comparison radiographs indicate that the continually treated rat femora were shorter than those of the pretreated and control groups.

The histological findings in our study suggest that there is an increase in the formation of bone as well as decreased resorption in the presence of pamidronate. This was found particularly in the endosteal region of the bone surrounding the lengthening as well as in the regenerate, and was more obvious in the operated leg. Other studies have recently suggested that bisphosphonates influence cells of osteoblastic lineage in a way distinct from their inhibitory effects on osteoclasts. ${ }^{24}$

Since pamidronate increased the bone-forming capacity of the regenerate, it is possible that its use may increase the risk of premature consolidation. The length of the regenerate was decreased by a mean of $0.8 \mathrm{~mm} \mathrm{(8 \% )} \mathrm{in} \mathrm{the} \mathrm{rabbits}$ given pamidronate. While this small amount is not alarming, the difference did reach statistical significance, such that careful observation for this possibility would be required if pamidronate were used clinically.

One rabbit given pamidronate sustained a femoral fracture in the operated limb on day 23. This may have been a random event, but it is possible that the bone was made brittle by the pamidronate.

We do not believe that the toxicological effects of bisphosphonates in children have yet been fully evaluated. We chose a dose of $3 \mathrm{mg} / \mathrm{kg}$ for this experiment based on the fact that this is the dose commonly given to children with osteogenesis imperfecta. ${ }^{13}$ Nephrocalcinosis is a potential concern but has not been reported in regimens of 6 to $12 \mathrm{mg} / \mathrm{kg} /$ year.

The large increase in BMD throughout the lengthened limb which we obtained after a single dose of pamidronate may have a positive therapeutic effect in children undergoing limb lengthening. Even more promising is that pamidronate increased the amount of regenerate which formed. Further investigations into the mechanical properties of the bone after treatment with pamidronate, refinement of the dosage regimen and the examination of possible toxicological effects are required before a clinical trial is undertaken. 
This study was funded in part by grants from the Australian Orthopaedic Association and the Children's Hospital Fund. Dr Cornell was funded by a contribution from Ingham Enterprises Pty Ltd. We would like to acknowledge the assistance of Troy James for his invaluable help in the ethical care of the rabbits.

No benefits in any form have been received or will be received from a commercial party related directly or indirectly to the subject of this article.

\section{References}

1. Aronson J, Harrison BH, Stewart CL, Harp JH. The histology of distraction osteogenesis using different external fixators. Clin Orthop 1989;241:106-16.

2. Ilizarov GA. The tension-stress effect on the genesis and growth of tissues. Part I: the influence of stability of fixation and soft-tissue preservation. Clin Orthop 1989;238:249-81.

3. Eyres KS, Bell MJ, Kanis JA. New bone formation during leg lengthening: evaluated by dual energy X-ray absorptiometry. $J$ Bone Joint Surg [Br] 1993;75-B:96-106.

4. Fleisch H. New bisphosphonates in osteoporosis. Osteoporosis Int 1993;3:Suppl 2:15-22.

5. Licata AA. Bisphosphonate therapy. Am J Med Sci 1997;313:17-22.

6. Fleisch HA. Bisphosphonates: preclinical aspects and use in osteoporosis. Ann Med 1997;29:55-62.

7. Allgrove J. Bisphosphonates. Arch Dis Child 1997;76:73-5.

8. Bellingham CM, Lee JM, Moran EL, Bogoch ER. Bisphosphonate (pamidronate/APD) prevents arthritis-induced loss of fracture toughness in the rabbit femoral diaphysis. J Orthop Res 1995;13:876-80.

9. Lee DY, Chung CY, Choi IH. Longitudinal growth of the rabbit tibia after callotasis. J Bone Joint Surg [Br] 1993;75-B:898-903.

10. Kassis B, Glorion C, Tabib W, Blanchard O, Pouliquen JC. Callus response to micromovement after elongation in the rabbit. $J$ Pediatr Orthop 1996;16:480-3.

11. Eyres KS, Bell MJ, Kanis JA. Methods of assessing new bone formation during leg lengthening: ultrasonography, dual energy x-ray absorptiometry and radiography compared. J Bone Joint Surg [Br] 1993;75-B:358-64.
12. Lu PW, Briody JN, Howman-Giles R, Trube A, Cowell CT. DXA for bone density measurement in small rats weighing 150 to 250 grams. Bone 1994;15:199-202.

13. Glorieux FH, Bishop NJ, Plotkin H, et al. Cyclic administration of pamidronate in children with severe osteogenesis imperfecta. $N$ Engl J Med 1998;339:947-52.

14. Goodship AE, Walker PC, McNally D, Chambers T, Green JR. Use of a bisphosphonate (pamidronate) to modulate fracture repair in ovine bone. Ann Oncol 1994;5Suppl7:53-5.

15. Li J, Mori S, Kaji Y, Mashiba T, Kawanishi J, Norimatsu H. Effect of bisphosphonate (incadronate) on fracture healing of long bones in rats. J Bone Miner Res 1999;14:969-79.

16. Lenehan TM, Balligand M, Nunamaker DM, Wood FE Jr. Effect of EHDP on fracture healing in dogs. J Orthop Res 1985;3:499-507.

17. Nyman MT, Paavolainen P, Lindholm TS. Clodronate increases the calcium content in fracture callus: an experimental study in rats. Arch Orthop Trauma Surg 1993;112:228-31.

18. Tarvainen R, Olkkonen $\mathbf{H}$, Nevalainen $\mathbf{T}$, et al. Effect of clodronate on fracture healing in denervated rats. Bone 1994;15:701-5.

19. Nyman MT, Paavolainen P, Lauren L, Arnala I. Short term clodronate treatment does not increase trabecular bone in post-traumatic osteopenia. Ann Chir Gynaecol 1995;84:296-301.

20. Nyman MT, Gao T, Lindholm TC, Lindholm TS. Healing of a tibial double osteotomy is modified by clodronate administration. Arch Orthop Trauma Surg 1996;115:111-4.

21. Peter CP, Cook WO, Nunamaker DM, et al. Effect of alendronate on fracture healing and bone remodelling in dogs. J Orthop Res 1996;14:74-9.

22. Miyazaki H, Hamanishi C, Yoshii T, Tanaka S. Effect of a single intravenous dose of bisphosphonate (pamidronate) on tibial cortical bone after lengthening. Acta Med Kinki Univ 1997;22:155-8.

23. Raggio CL, Camacho NP, Zraick V. Alendronate reduces fractures without increasing bone strength in a growing mouse model of osteogenesis imperfecta. Procs Pediatric Orthopaedic Society of North America, 1999.

24. Giuliani N, Pedrazzoni M, Negri G, et al. Bisphosphonates stimulate formation of osteoblast precursors and mineralized nodules in murine and human bone marrow cultures in vitro and promote early osteoblastogenesis in young and aged mice in vivo. Bone 1998;22:455-61. 